$16^{\text {th }}$ International Conference on

AEROSPACE SCIENCES \& AVIATION TECHNOLOGY, $\boldsymbol{A S A T}$ - 16 - May 26 - 28, 2015, E-Mail: asat@mtc.edu.eg Military Technical College, Kobry Elkobbah, Cairo, Egypt Tel : +(202) 24025292 - 24036138, Fax: +(202) 22621908

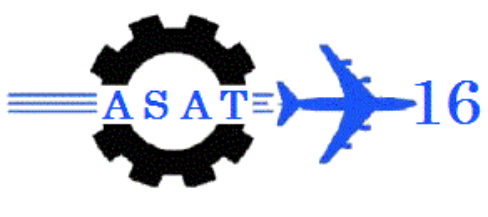

\title{
Modeling of Hydrogas Unit for Tracked Vehicle Suspension
}

\author{
H. A. Hammad ${ }^{*}$, A. M. Salem ${ }^{\square}$, I. Saleh Mostafa ${ }^{\diamond}$, I. A. Elsherif ${ }^{\circ}$.
}

\begin{abstract}
Tracked vehicles equipped with conventional suspension are limited in their ability to achieve high mobility. This limitation is due to the linear characteristics and the consequent poorer ride performance [1-3]. Hydro gas suspension due to their inherent non-linear behavior can provide higher mobility and better ride comfort performance [4]. This paper aims to evaluate the characteristics of hydro-gas suspension system and apply this nonconventional system for the armored fighting carrier BMP-1. To achieve this goal, theoretical and experimental studies were carried out. The theoretical study includes modeling of the hydro gas suspension unit mathematically and validation of the developed model using MATLAB/SIMULINK. The experimental measurements are carried out to validate the results obtained from the model. The force, created inside the hydro gas unit during its action, includes the elastic and damping forces, the variation of such force with displacement and velocity of moving part are recorded (obtained). This variation is used as input parameters in the equation of oscillation of vehicle hull to study its vibration response. The obtained results show that the proposed hydro gas suspension system is more acceptable than the conventional one.
\end{abstract}

Keywords: tracked vehicle suspension, hydrogas suspension system, hedrogas unit.

\section{Nomenclature}

$\mathrm{A}_{\mathrm{o}} \quad$ area of orifice, $\mathrm{m}^{2}$

$\mathrm{A}_{\mathrm{f}} \quad$ area of floating piston, $\mathrm{m}^{2}$

$\mathrm{A}_{\mathrm{p}} \quad$ area of the piston, $\mathrm{m}^{2}$

$\mathrm{A}_{\mathrm{r}} \quad$ area of rod, $\mathrm{m}^{2}$

B Bulk's modulus of oil, $\mathrm{Pa}$

$\mathrm{C}_{\mathrm{d}} \quad$ discharge coefficient

$\mathrm{C}_{\mathrm{V}} \quad$ viscous friction coefficient for the piston, Ns/m

Ff viscous friction coefficient for the floating piston, $\mathrm{Ns} / \mathrm{m}$

$\mathrm{m}_{\mathrm{f}} \quad$ mass of floating piston, $\mathrm{kg}$

$\mathrm{m}_{\mathrm{p}} \quad$ mass of piston, $\mathrm{kg}$

Q flow rate of oil through the orifices, $\mathrm{m}^{3} / \mathrm{s}$

$\mathrm{P}_{1} \quad$ pressure in the lower fluid chamber, pa

$\mathrm{P}_{2} \quad$ pressure in the upper fluid chamber, pa

$\mathrm{P}_{\mathrm{g}} \quad$ nitrogen gas pressure in the nitrogen chamber, pa

$\mathrm{P}_{\mathrm{o}} \quad$ initial pressure of nitrogen gas in nitrogen chamber, pa

$\mathrm{V}_{1} \quad$ volume of lower chamber, $\mathrm{m}^{3}$

$\mathrm{V}_{2} \quad$ volume of upper chamber, $\mathrm{m}^{3}$

$\mathrm{V}_{\mathrm{o}} \quad$ initial volume of nitrogen chamber, $\mathrm{m}^{3}$

$\mathrm{V}_{\mathrm{g}} \quad$ volume of nitrogen in nitrogen chamber, $\mathrm{m}^{3}$

$\mathrm{X}$ displacement of floating piston, $\mathrm{m}$

$\mathrm{Z}$ displacement of the rod, $\mathrm{m}$

HSU Hydro gas Suspension Unit

\footnotetext{
*Egyptian Armed Forces.
} 


\section{Introduction}

As the operating speed of high mobility tracked vehicle increases, the vibration induced by rough road condition also increases and it induces fatigue on crew members and many delicate instruments inside the vehicle. Also, vibration in a gun barrel reduces the shooting accuracy. Excessive vibration in high mobility tracked vehicle limits the maximum vehicle speed and consequently reduces the survivability and operational efficiency in combat situations [5]. Consequently, the vehicle suspension system is needed to operate on different kinds of terrain conditions including on roads and off-roads.

The mobility performance of high mobility tracked vehicles is often limited by the operator's endurance to withstand the transmitted shocks and vibrations, and his ability to maintain control. With a continual demand for increased power to weight ratio and higher speeds, the present trend is towards the use of advanced suspension systems such as hydro gas or hydro pneumatic suspension. These tend to be lighter and more compact; can be mounted outside the hull, incorporate integral damping arrangements, and offer load-leveling capabilities due to their non linear progressively stiffening spring characteristics [6]. In this type of suspension, gas is used as a spring medium and hydraulic oil is utilized for force transmitting and dampening out the oscillations. The advantage of employing the hydro gas suspension in a tracked vehicle is not only to isolate the primary vibrations induced into the suspension system but also to offer a better ride comfort through nonlinear springing of the gas chamber. The design principle of hydro-pneumatic unit is as the road wheel rises, the axle arm is lifted and this rotates the crank which moves the piston via the connecting rod, the piston displaces oil through the damper valve and moves the separator piston as illustrated in figure (1).

The hydrogas suspension unit contains both hydraulic fluid and compressed gas, usually nitrogen [7], separated by either a floating piston or a flexible diaphragm. The suspension forces are generated by pressure drop acting on the main piston. Damping forces are generated by the flow of hydraulic fluid through constrictions provided by either a damper plate or valve housing, while restoring forces are generated by compression and extension of the gas charge.

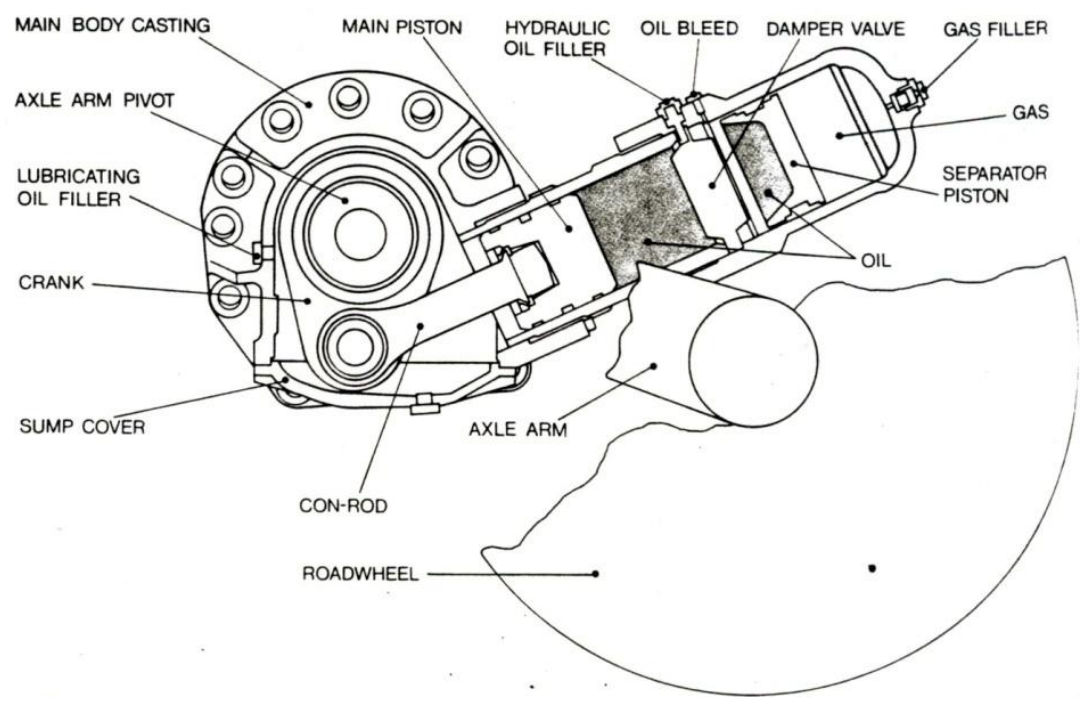

Fig. 1. main components of hydro-gas suspension system.

\section{Mathematical modeling of hydro-gas suspension unit.}

Figure (2) shows a functional scheme of the studied hydro gas suspension unit, the coordinate $\mathrm{X}$ represents the displacement of floating piston while $\mathrm{Z}$ coordinate represents the displacement of the moving rod. 


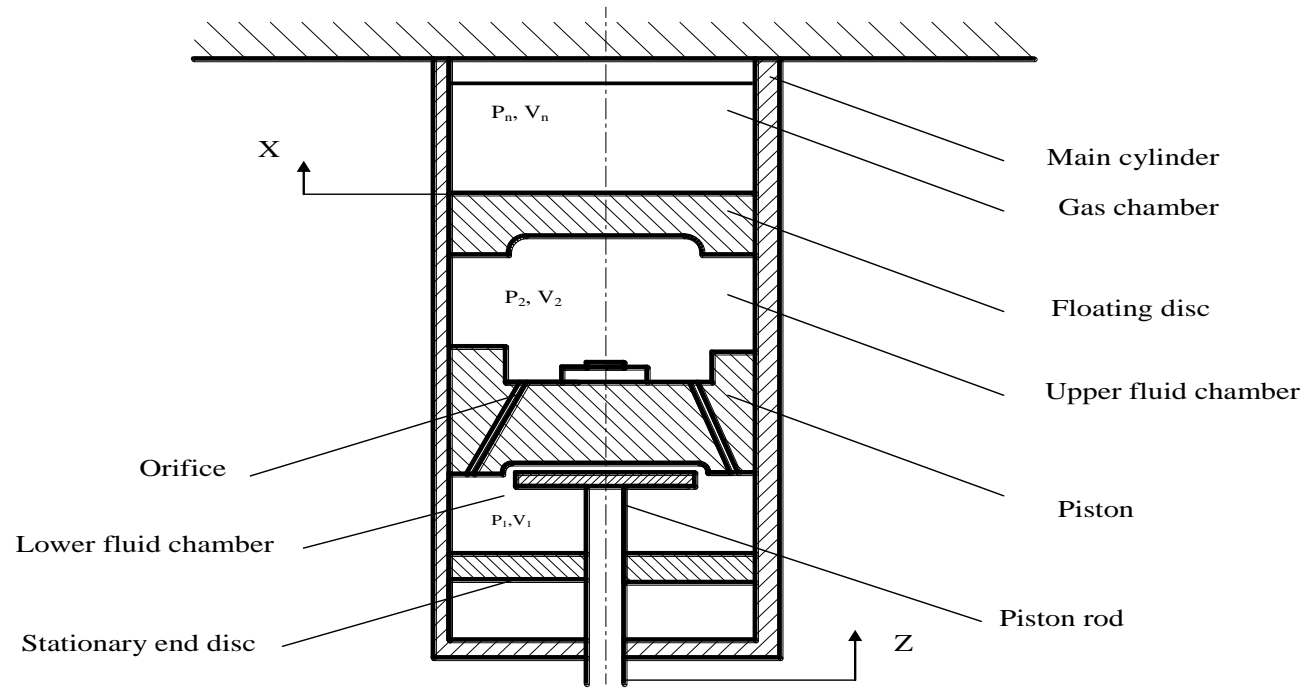

Fig. 2. scheme of the hydro gas suspension unit.

The mathematical model is developed by deriving the equations describing the dynamic behavior of suspension unit.

The following assumptions were considered for developing the mathematical model [8-10]:

1- The density and bulk's modulus of oil are constant.

2- Coefficient of discharge $\left(\mathrm{C}_{\mathrm{d}}\right)$ is assumed constant.

3 - The variation of the viscosity of oil is neglected.

4- Negligible leakage flow rate.

5- Polytropic process for the gas compression and expansion.

\subsection{Fundamental equations [11-14]}

The flow rate through the orifices of hydro gas unit is given by the following equation:

$$
Q=C_{d} \quad A_{O} \sqrt{\frac{2\left(P_{2}-P_{1}\right)}{\rho}}
$$

While, the Continuity equation in upper chamber is expressed by:

$$
\begin{aligned}
& A_{p} \frac{d Z}{d t}=2 Q+A_{f} \frac{d X}{d t}+\left(\left(V_{2}-A_{p} Z+A_{f} X\right) / \beta\right) \frac{d P_{2}}{d t} \\
& A_{p} \frac{d Z}{d t}-2 Q-A_{f} \frac{d X}{d t}-\left(\left(V_{2}-A_{p} Z+A_{f} X\right) / \beta\right) \frac{d P_{2}}{d t}=0
\end{aligned}
$$

The Continuity equation in lower chamber can be expressed by:

$$
\begin{aligned}
& 2 Q=\left(A_{p}-A_{r}\right) \frac{d Z}{d t}+\left(\left(V_{1}+\left(A_{p}-A_{r}\right) Z\right) / \beta\right) \frac{d P_{1}}{d t} \\
& 2 Q-\left(A_{p}-A_{r}\right) \frac{d Z}{d t}-\left(\left(V_{1}+\left(A_{p}-A_{r}\right) Z\right) / \beta\right) \frac{d P_{1}}{d t}=0
\end{aligned}
$$

The equation of motion describes the floating piston movement is:

$$
m_{f} \frac{d^{2} X}{d t^{2}}=\left(P_{2}-P_{g}\right) A_{f}-m_{f} g-f_{f} \frac{d X}{d t}
$$

The volume of the nitrogen gas inside the chamber is given by:

$$
V_{g}=V_{o}-A_{f} X
$$

Therefore, the nitrogen gas pressure is determined from the equation

$$
P_{o} V_{o}^{1.35}=P_{g} V_{g}^{1.35}
$$


Equation of motion of piston is represented by:

$$
m_{p} \frac{d^{2} Z}{d t^{2}}=P_{1}\left(A_{p}-A_{r}\right)-P_{2} A_{p}-C_{V} \frac{d Z}{d t}
$$

The parameters of the hydro gas suspension unit model are as follows:

\begin{tabular}{|c|l|c|l|}
\hline symbols & \multicolumn{1}{|c|}{ values } & Symbols & \multicolumn{1}{|c|}{ values } \\
\hline $\mathrm{A}_{\mathrm{o}}$ & $2.009 * 10^{-6} \mathrm{~m}^{2}$ & $\mathrm{~m}_{\mathrm{p}}$ & $0.05 \mathrm{~kg}$ \\
\hline $\mathrm{C}_{\mathrm{d}}$ & 0.65 & $\mathrm{~A}_{\mathrm{r}}$ & $9.5^{*} 10^{-5} \mathrm{~m}^{2}$ \\
\hline$\rho$ & $850 \mathrm{~kg} / \mathrm{m}^{3}$ & $\mathrm{P}_{\mathrm{o}}$ & $2 \mathrm{Mpa}$ \\
\hline $\mathrm{A}_{\mathrm{p}}$ & $1.0178^{*} 10^{-3} \mathrm{~m}^{2}$ & $\mathrm{~V}_{\mathrm{o}}$ & $20.4 * 10^{-5} \mathrm{~m}^{3}$ \\
\hline $\mathrm{A}_{\mathrm{f}}$ & $9.621 * 10^{-4} \mathrm{~m}^{2}$ & $\mathrm{f}_{\mathrm{f}}$ & $0.3 \mathrm{Ns} / \mathrm{m}$ \\
\hline$\beta$ & $1.3 * 10^{9} \mathrm{pa}$ & $\mathrm{C}_{\mathrm{v}}$ & $0.25 \mathrm{Ns} / \mathrm{m}$ \\
\hline $\mathrm{m}_{\mathrm{f}}$ & $0.055 \mathrm{~kg}$ & & \\
\hline
\end{tabular}

The previous equations were solved by using simulink program in MATLAB.The input parameters of this program are the displacement and the velocity of the moving part.

\section{Experimental investigation.}

The shock absorber dynamic characteristics are evaluated experimentally by measuring the hydro gas suspension unit force versus displacement and velocity. The damper test system type 850 MTS shown in figure (3) is used to measure these parameters. The HSU is subjected to input displacement in the form of sinusoidal signal, with different amplitudes and frequencies representing the road configuration.

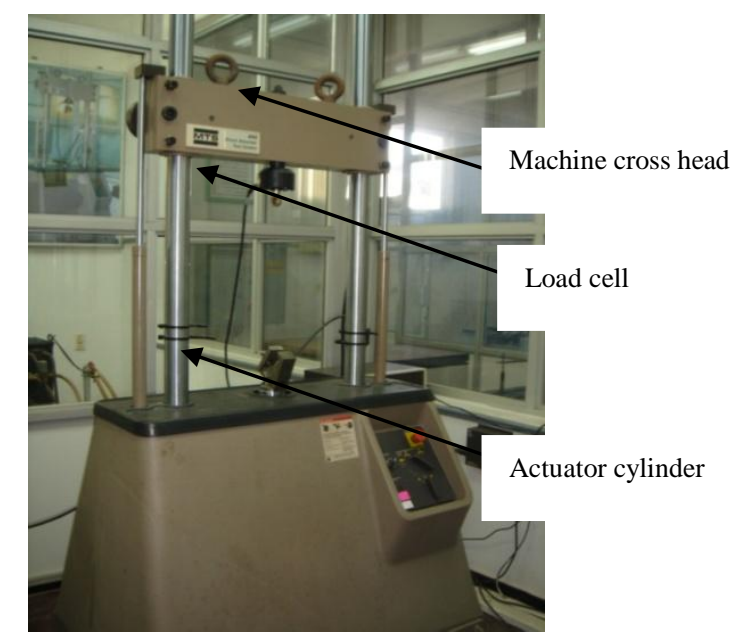

Fig. 3. damper test system MTS 850.

The stroke of the hydro-gas suspension unit is measured with vernire caliper and is marked using a mark pin at its mid distance.

The upper end of the hydro-gas suspension unit is connected to the load cell in the machine crosshead while the lower end is connected to the actuator cylinder.

The crosshead is unlocked so that the piston can be compressed to its mid stroke, and then it is hydraulically locked from the control panel.

The shape of the wave type, frequency and amplitude of excitation are defined as an input data test file.

The test file is loaded to operate the machine and execute the predefined test. 
The damping force is generated and the displacement, velocity of the piston is recorded through the data accusation system.

\subsection{Test results}

The experimental results are shown in figures (4-7); the figures show the variation of the HSU force with the piston velocity and displacement at different frequencies and amplitudes. The amplitude of sinusoidal excitation was varied to be $(40,60,80,100$, 120) $\mathrm{mm}$ while the frequencies of excitation is changed to be $(0.5,1,1.5,2,2.5,3,4)$ $\mathrm{Hz}$. The figures illustrated the test results at $(60,100) \mathrm{mm}$ amplitudes and $(1,2) \mathrm{Hz}$ of frequency.

\subsection{Effect of excitation frequency.}

Figure (4) shows the variation of hydro gas suspension unit force with velocity at different frequencies and at amplitudes $(60,100) \mathrm{mm}$ while figure (5) shows the variation of hydro gas suspension unit force with displacement.

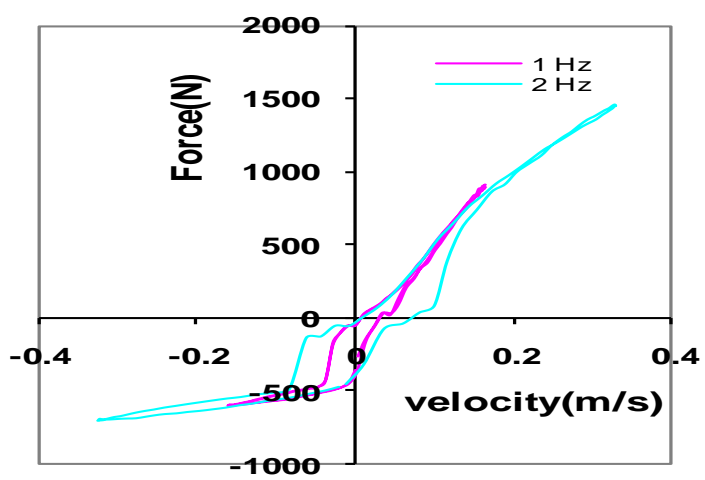

a) $60 \mathrm{~mm}$ amplitude

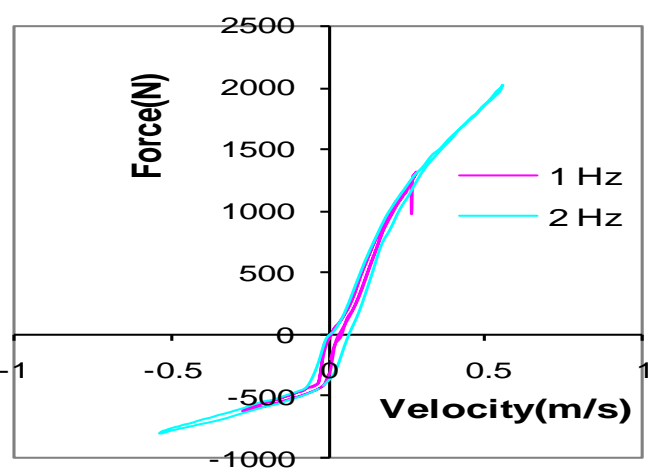

b) $100 \mathrm{~mm}$ amplitude

Fig. 4. Variation of HSU force with velocity at different frequencies.

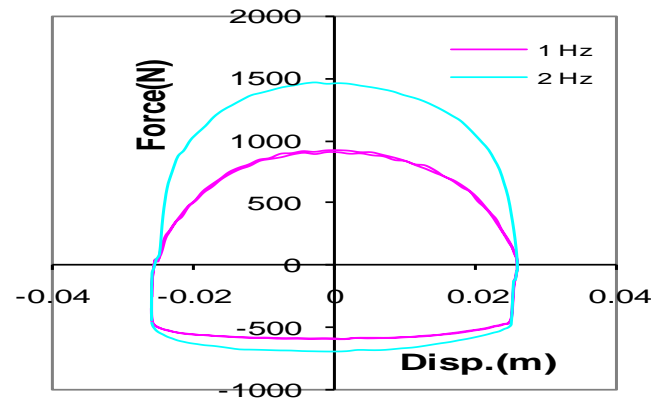

a) $60 \mathrm{~mm}$ amplitude

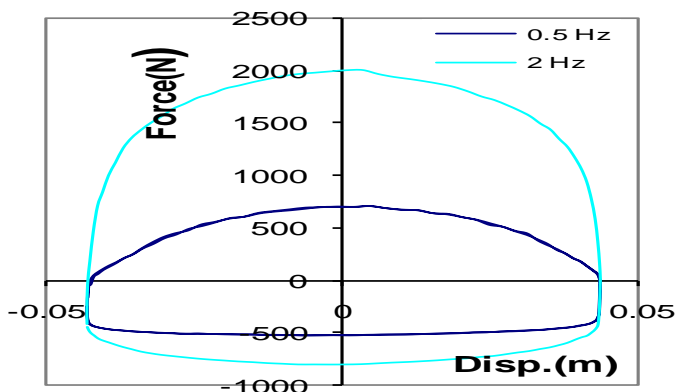

b) $100 \mathrm{~mm}$ amplitude

Fig. 5. variation of HSU force with displacement at different frequencies.

\subsection{Effect of excitation amplitude:}

Figure (6) illustrates the variation of hydro gas suspension unit force with velocity at different amplitudes and at frequencies $(1,2) \mathrm{Hz}$ while figure (7) shows the variation of hydro gas suspension unit force with displacement. 


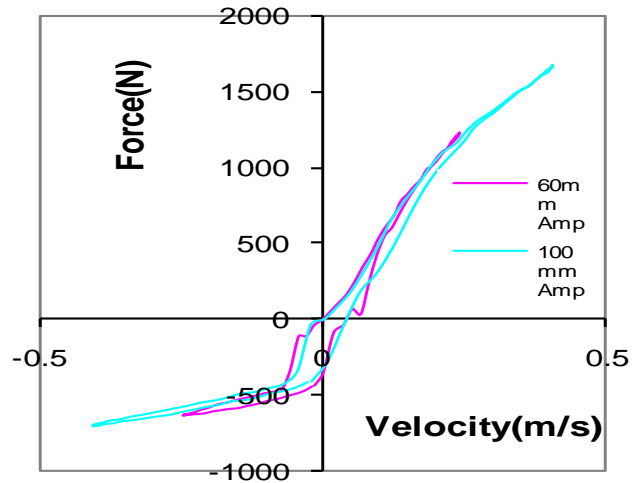

a) $2 \mathrm{~Hz}$

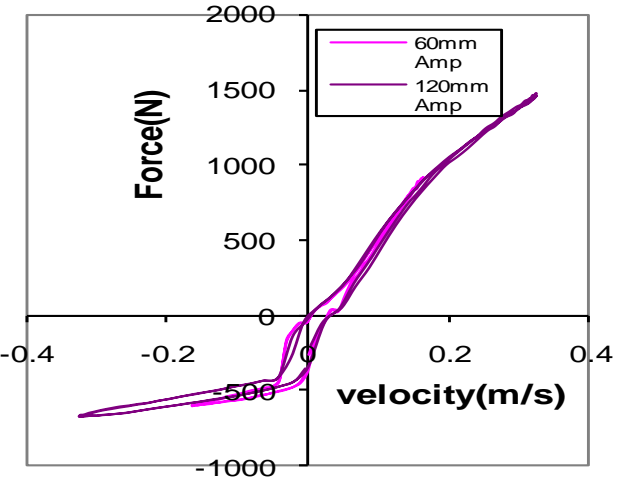

b) $1 \mathrm{~Hz}$

Fig. 6. Change of HSU force with velocity at different amplitudes.

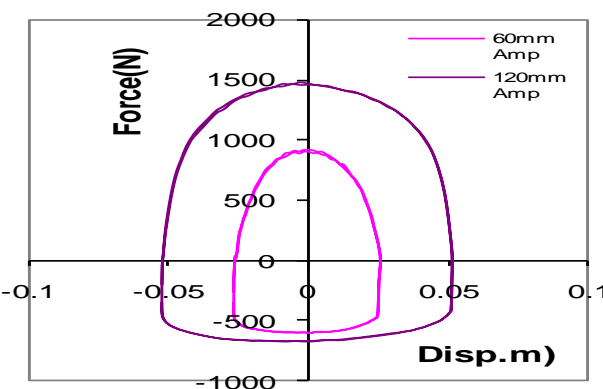

a) $1 \mathrm{~Hz}$

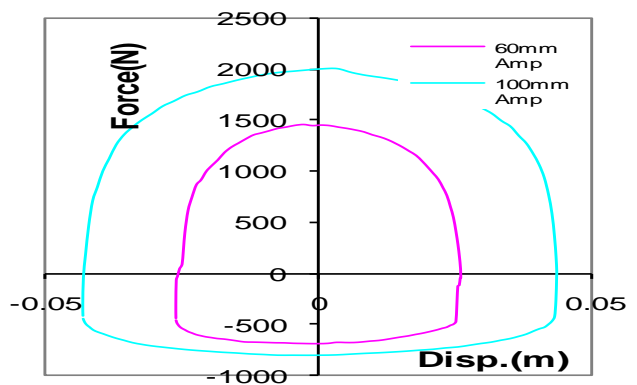

b) $2 \mathrm{~Hz}$

Fig. 7. Change of HSU force with displacement at different amplitudes.

The hydro gas suspension unit force with positive velocity represents the rebound stroke while the force with negative velocity represents the compression stroke.

During the compression stroke, the hydro-gas suspension unit generates lower damping force in comparison with the generated damping force in the rebound stroke.

The maximum damping forces in the rebound and compression strokes were found at the middle distance of unit stroke.

It is found that for a low frequency range $(0.5$ to $4 \mathrm{~Hz})$, the influence of the amplitude and frequency on the hydro gas suspension unit force is very low consequently, it can be neglected.

The relation between hydro gas suspension unit force and velocity have a nonlinear form for both rebound and compression strokes. Consequently, the value of the damping coefficient of the hydro-gas unit is not constant.

\section{Comparison between the experimental results and simulation}

Figures (8) show the variation of hydro-gas suspension unit force with time, piston velocity, and piston displacement respectively. By comparing the experimental results with those of the numerical simulation. It can be found that there is a good agreement between the two results; accordingly, the numerical simulation can approximately simulate the actual characteristics of the hydro gas suspension unit. The little distortion in simulating results may be due to the compressibility of oil not being very accurate introduced. The research on more accurate mathematical model of the hydro-gas suspension unit will be included in a future work. 


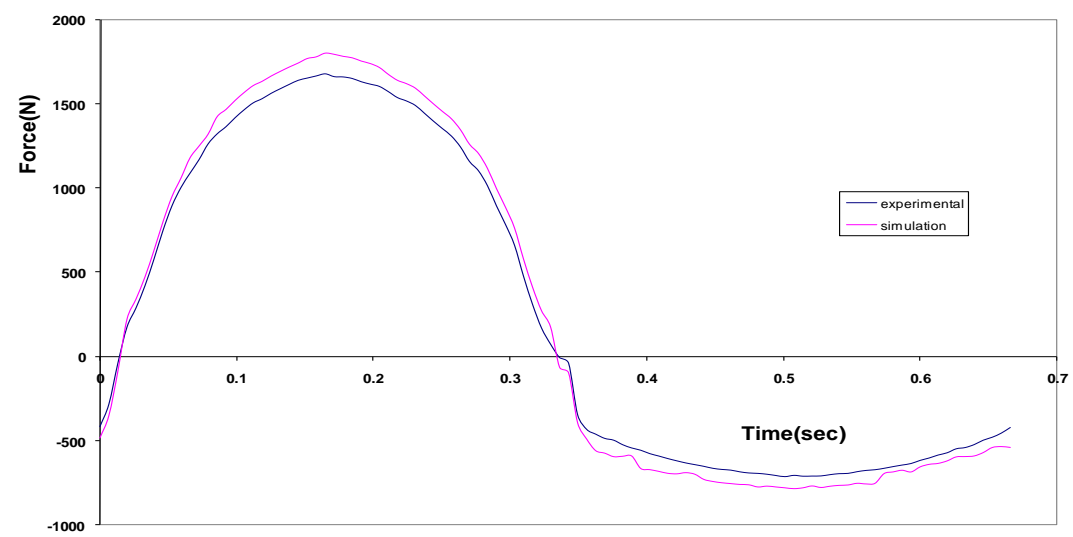

variation of HSU force with time

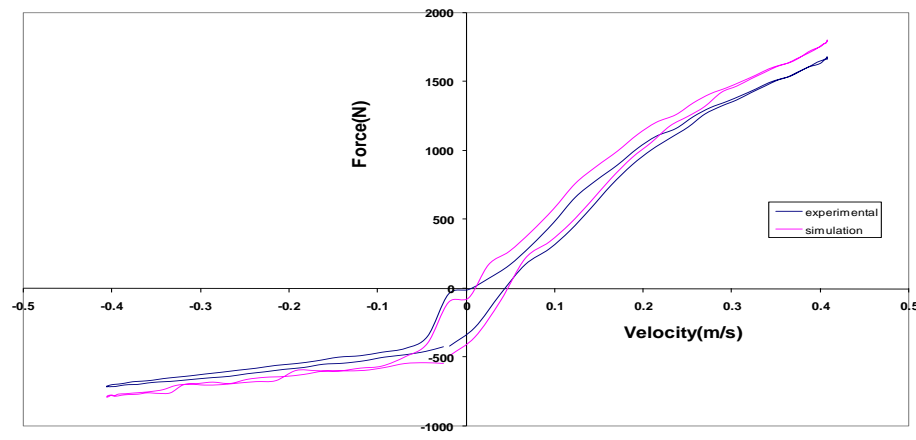

variation of HSU force with piston velocity

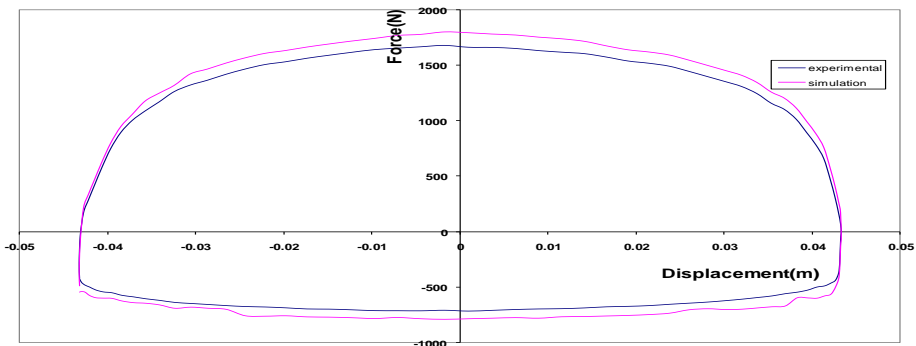

variation of HSU force with displacement

Fig. 8. Variation of hydro-gas suspension unit force with time, piston velocity, and piston displacement respectively.

5. Variation of hydro gas suspension unit force with piston displacement.

The important result obtained from studying the modeled hydro gas suspension unit is that, the force of the hydro-gas unit is a function of piston displacement [15,16]. Figure (9) illustrates the relation between the hydro gas suspension unit force and the displacement of its piston due to sinusoidal displacement input excitation, the equation representing this relation can be obtained using curve fitting as: 


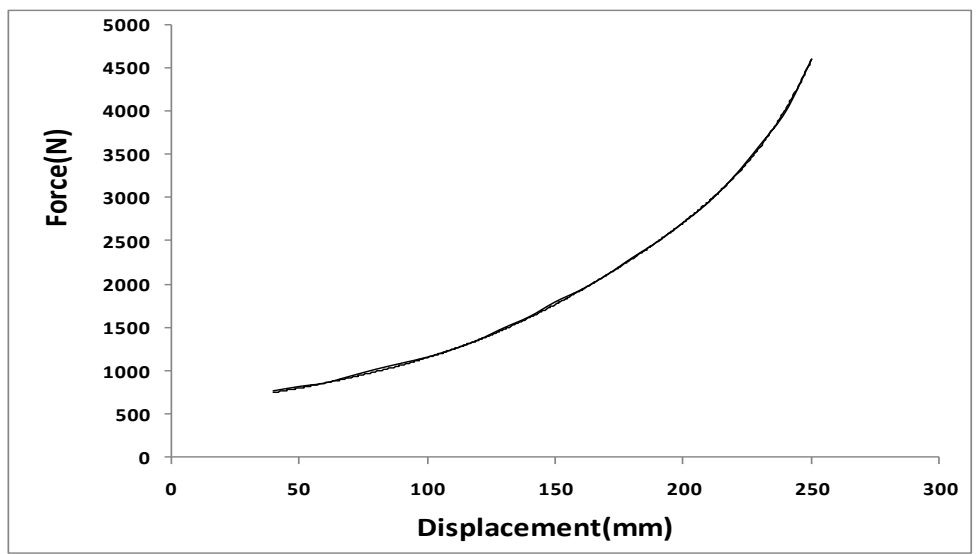

Fig. 9. Variation of HSU force with displacement

$F_{u}=c_{1} d^{4}-c_{2} d^{3}+c_{3} d^{2}-c_{4} d+c_{5}$

Where $F_{u}$ is the hydro gas unit force while $d$ is the piston displacement. The constants $c_{1}$ to $c_{5}$ are determined according to the type of curve fitting.

For different values of the road wheel vertical displacement, it is possible to calculate the corresponding values of hydro gas suspension unit force (required force) and express graphically the relationship between required force and corresponding displacement as shown in figure (10).

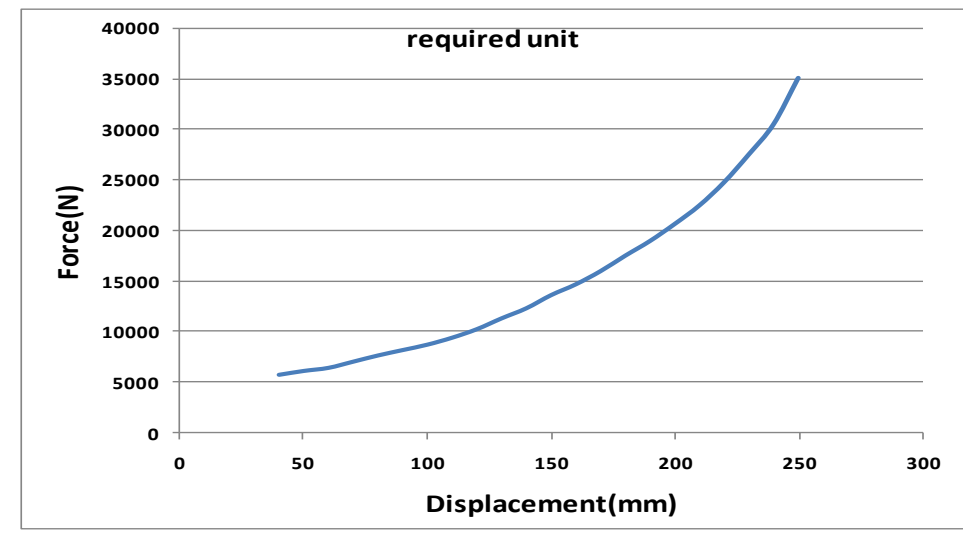

Fig. 10. Variation of HSU force at road wheel and corresponding vertical shift.

\section{Evaluation of Tracked Vehicle hydrogas Suspension Performance under Periodic Terrains profile.}

This section presents the results obtained from the simulation for the suspension performance under sinusoidal road excitations for both studied suspensions (conventional - hydrogas). For this purpose of study, an in-plane dynamic model of a typical off-road tracked vehicle, AFVBMP, is developed in MATLAB/Simulink environment. Figure (11-a,b) illustrates a half model of the vehicle with hull mass $\left(\mathrm{m}_{\mathrm{b}}\right)$ and mass moment of inertia $\left(\mathrm{J}_{\mathrm{y}}\right)$ is supported by 6 road wheels with mass $\left(\mathrm{m}_{\mathrm{w}}\right)$ and wheel stiffness $\left(\mathrm{K}_{\mathrm{w}}\right)$. The model is symmetry about a vertical axis passing through the centre of gravity (C.G) of the hull mass. In addition, it has 8DOF, vertical bounce \& pitch angle associated with hull mass and 6 DOF (vertical bounce) of road wheels.

The differential equations governing the suspension model are expressed on the basis of Newton's Second Law of motion. Also, in the development of the model, the following assumptions are considered:

1- The hull body mass element is assumed to be rigid body. 
2- The torsion bars are represented by independent linear springs.

3- The shock absorbers represent the damping elements have constant damping coefficients.

4- The road wheel tyres are assumed to be much more rigid than the torsion bars.

5- The effect of the track on the dynamics of the suspension is not considered.

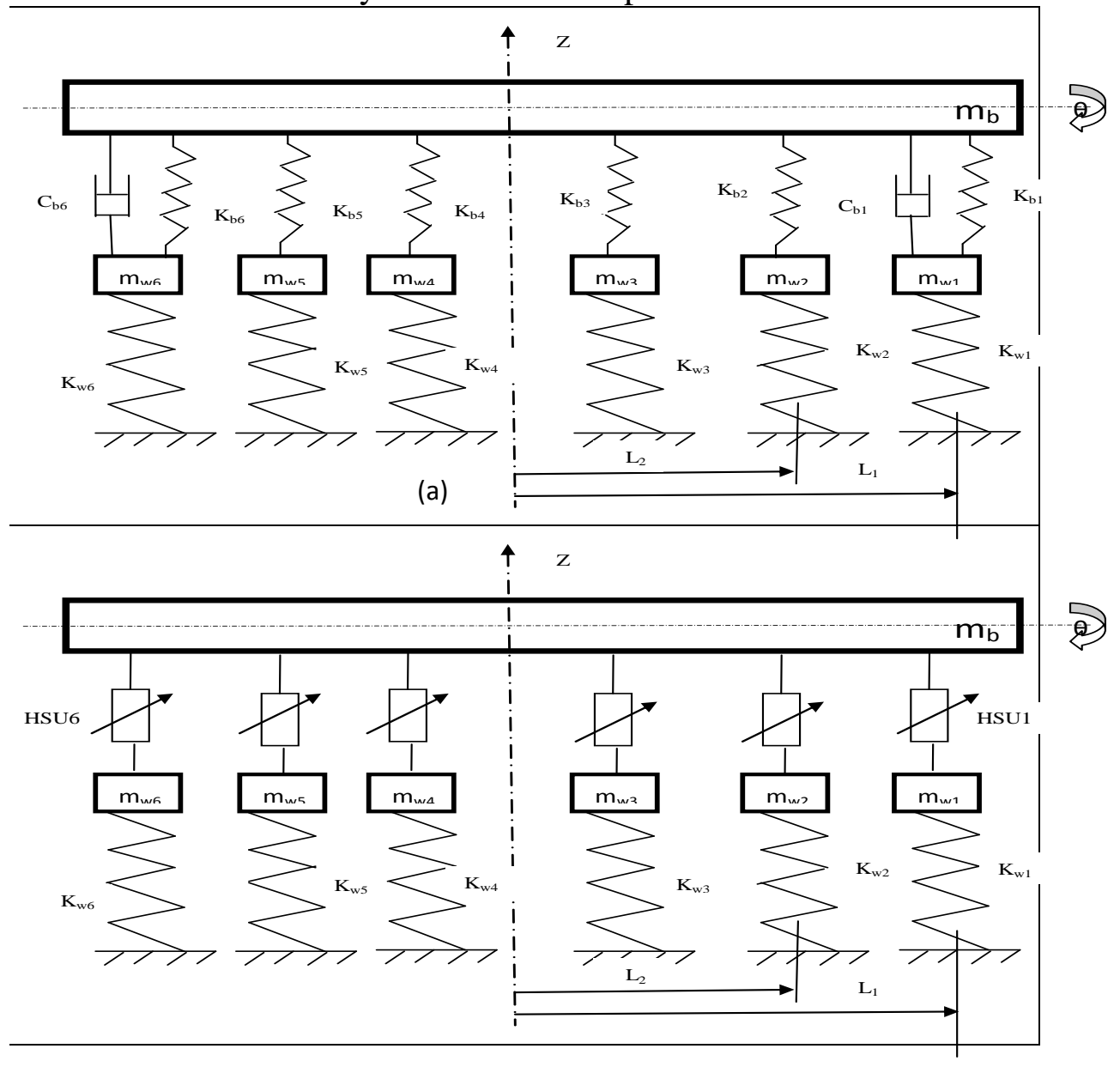

(b)

Fig. 11. Six- station vehicle suspension model

a) Conventional b) proposed hydrogas.

The equations of the bounce and pitch angle of the body in addition to the bounce of each road wheel are expressed as follows:

- Conventional suspension system.

Bounce motion of the hull:

$m_{b} Z_{B} \ddot{+}+\sum_{1}^{2} C_{b i}\left(\dot{z}_{b} l_{i} \dot{\Phi}-Z_{w l}\right)+\sum_{1}^{6} K_{b i}\left(Z_{b}+l_{i} \Phi-Z_{w i}\right)=0$

Pitch motion of the hull:

$J_{Y} \ddot{\Phi}+\sum_{1}^{2} C_{b i}\left(\dot{Z}_{b}+l_{i} \dot{\Phi}-\dot{Z}_{w_{i}}\right) l_{i}+\sum_{1}^{6} K_{b i}\left(Z_{b}+l_{i} \Phi-Z_{w i}\right) l_{i}=0$

Bounce of $\mathrm{i}^{\text {th }}$ road wheel:

$m_{w i} \ddot{Z}_{w l}-C_{b i}\left(\dot{Z}_{b}+l_{i} \dot{\Phi}-\dot{Z}_{w i}\right)-K_{b i}\left(Z_{b}+l_{i}-Z_{w i}\right)+K_{w i}\left(Z_{w i}-Z_{r i}\right)=0$

The proposed hydrogas suspension system is modeled as replacement the conventional suspension by hydrogas suspension unit at each road wheel instead of torsion bar, the equations of motion as follows:

Bounce motion of the hull: 
$m_{b} \ddot{z}_{b}+2 \sum_{1}^{6} F_{u i}=0$

$F_{u i} \ldots \ldots \ldots .$. HSU force of $\mathrm{i}^{\text {th }}$ unit, $\mathrm{i}=1, \ldots ., 6$.

$J_{y} \ldots \ldots \ldots$. Hull mass moment of inertia.

Pitch motion of the hull:

$J_{y} \ddot{\Phi}+2 \sum_{1}^{6} F_{u i} \cdot\left(L_{i} \varnothing\right)=0$

Bounce of $i^{\text {th }}$ road wheel:

$m_{w} Z_{w}+K_{w}\left(Z_{w i}-Z_{r i}\right)=0$

All the variables and parameters in these equations are defined in Table 1 which also states their typical values used in the simulations.

Table 1 Half model suspension parameters for tracked vehicle [2]

\begin{tabular}{c|c|c}
\hline \hline Description & sympol & values \\
\hline Body mass $(\mathrm{kgm})$ & $\mathrm{m}_{\mathrm{b}}$ & 6400 \\
\hline Body moment of inertia about lateral axis $\left(\mathrm{kg} \cdot \mathrm{m}^{2}\right)$ & $\mathrm{J}_{\mathrm{y}}$ & 58673.3 \\
\hline Mass of $\mathrm{i}^{\text {th }}$ road wheel $(\mathrm{kg})$ & $\mathrm{m}_{\mathrm{wi}}$ & 150 \\
\hline Equivalent stiffness of $\mathrm{i}^{\text {th }}$ wheel $(\mathrm{N} / \mathrm{m})$ & $\mathrm{k}_{\mathrm{wi}}$ & 613000 \\
\hline $1^{\text {st }}$ wheel centre $(\mathrm{m})$ & $\mathrm{L}_{1}$ & 1.65 \\
\hline $2^{\text {nd }}$ wheel centre $(\mathrm{m})$ & $\mathrm{L}_{2}$ & 0.99 \\
\hline $3^{\text {rd }}$ wheel centre $(\mathrm{m})$ & $\mathrm{L}_{3}$ & 0.33 \\
\hline $4^{\text {th }}$ wheel centre $(\mathrm{m})$ & $\mathrm{L}_{4}$ & 0.33 \\
\hline $5^{\text {th }}$ wheel centre $(\mathrm{m})$ & $\mathrm{L}_{5}$ & 1.07 \\
\hline $6^{\text {th }}$ wheel center $(\mathrm{m})$ & $\mathrm{L}_{6}$ & 1.81 \\
\hline \hline
\end{tabular}

\section{Simulink model}

This section presents the Simulink model of the suspension systems of the tracked vehicle. The model is developed directly from the differential equations of motions that describe the physical model. The Simulink toolbox within MATLAB is used to build the block diagrams that describe the model equations. The suspension model shown in figure (12) represents the top-level diagram of the suspension system. The equations are implemented in the Simulink through the straightforward use of Gain and Summation blocks to give the body bounce and angular motions.
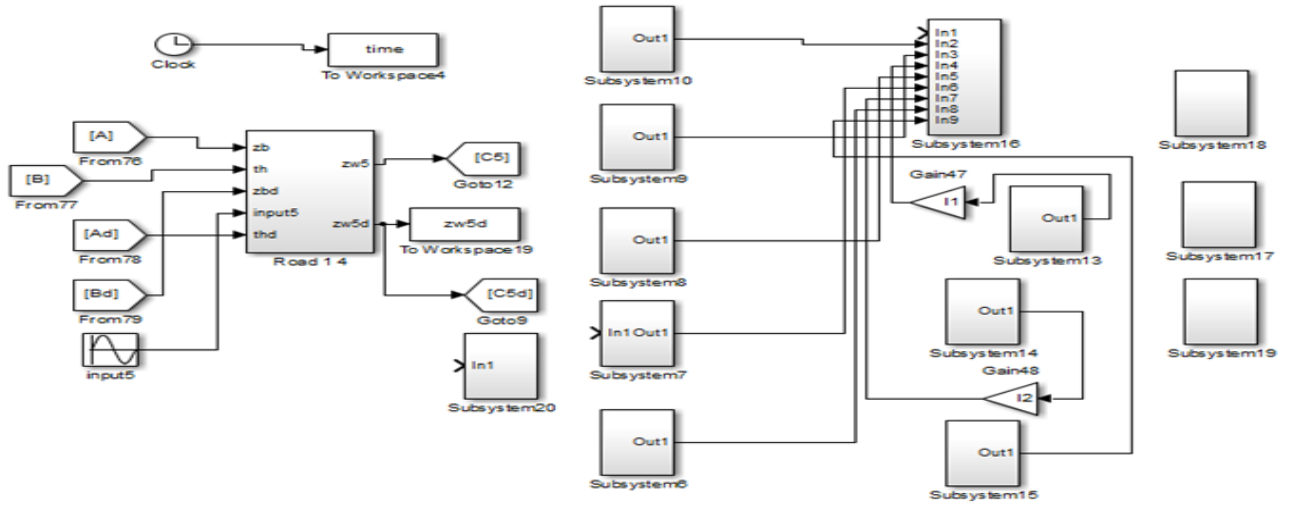

Fig. 12. schematic diagram of the simulink program 


\section{Comparison between conventional and hydro gas suspension systems.}

The effectiveness of the proposed suspension with hydrogas unit is quantified when the vehicle crosses a sinusoidal road excitation.

Figure (13-a, b) shows the amplitude and frequency response of the vehicle hull AFV BMP-1.

A reasonable improvement in the body vertical displacement and body angular acceleration responses is achieved for the suspension with hydrogas suspension compared to the conventional suspension.

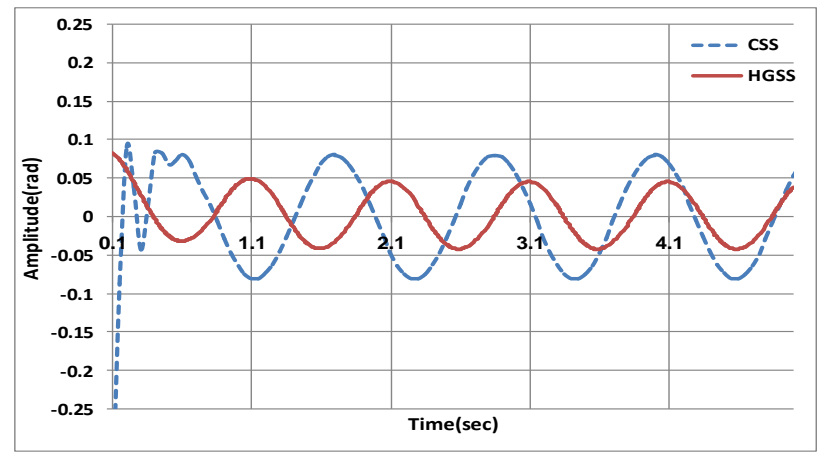

(a)

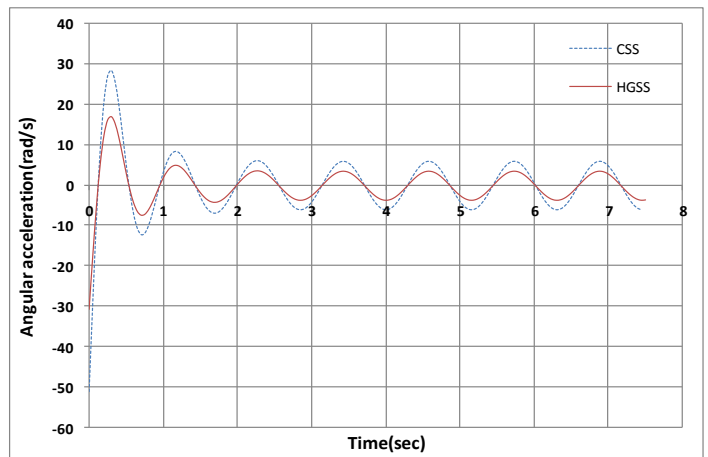

(b)

Fig. 13. Response of vehicle hull in both cases of conventional and hydrogas suspensions.

\section{Conclusions}

The hydro gas suspension system equipped with the armor personnel carrier BMP-1 instead of the conventional suspension system is studied, the study is based on the studied proposed hydro gas suspension unit dynamic characteristics. The dynamic behavior of hydro gas suspension unit was investigated theoretically and experimentally. The theoretical study included the deduction of a mathematical model describing the hydro gas unit dynamic behavior and the development of a simulation program using the MATLAB package. An input sinusoidal displacement was experimentally applied to the hydro gas suspension unit. The variation of hydro gas suspension unit force was measured for different amplitudes and frequencies of input displacement. The simulation results showed good agreement with the experimental results, which validates the developed simulation program.

The proposed hydro gas suspension provides decreasing the amplitude of angular body displacement by compared with conventional suspension.

The vehicle hull acceleration with hydro gas suspension is smaller than the conventional suspension by this means that the comfort ability of the vehicle with hydro gas suspension is increased.

\section{REFERENCES.}

1- Printed lecture of tanks department, Ineory of suspension, chair of tanks, M.T.C., Cairo, Egypt.

2- Printed lecture of tanks department, Construction of Tracked Vehicles, part II, chair of tanks, M.T.C, Cairo, Egypt, 1995.

3- Janes's armored and artillery upgrades, twelfth edition, ISBN, (1999-2000), pp.324328.

4- Yoonsun Kim, Youngjin Park, "Preview control of high mobility tracked vehicle suspension", The First Asian Conference on Multibody Dynamics, Iwaki, Fukushima, Japan, 31-August 2, 2002, pp.3-5. 
5- ANIL DHIR and SESHADRI SANKAR, "Assessment of Tracked Vehicle Suspension System Using A Validated Computer Simulation Model", Journal of Terramechanics, Vol. 32, No. 3, pp. 127-149, 1995.

6- S.Sridhar, N.S.Sekar, "Optimization of Kinematics for Tracked Vehicle Hydro Gas Suspension System", Defence Science Journal, Vol. 56, No 5, pp. 743-752. November 2006.

7- Christiaan Lambert Giliomee, "ANALYSIS OF A FOUR STATE SWITCHABLE HYDRO-PNEUMATIC SPRING AND DAMPER SYSTEM", , University of Pretoria, Copyright 2003, pp.6-12.

8- S. Subramanian, R. Surampudi and K. R. Thomson, "Development of a Nonlinear Shock Absorber Model for Low-Frequency NVH Applications", DaimlerChrysler Corporation, 2003.

9- W. Schiehlen, B.Hu," Spectral simulation and shock absorber identification", University of Stuttgart, International Journal of Non-Linear Mechanics, pp.161-171, 38 (2003).

10- David J. Purdy, Rajesh Kumar, "Mathematical Modeling of A Hydro-Gas Suspension Unit for Tracked Military Vehicles", Journal of Battlefield Technology Vol. 8, No 3, November 2005, pp. 7-14

11- R. Shankar, "Future combat systems for futuristic infantry combat vehicles, technology ISSN: 0971-4413.

12- Pankaj k. S. Lakashmanan, "Design of a hydro strut suspension in a tracked vehicle to maximize rider comfort and high speeds on cross country terrain", the First Asian Conference on Multibody Dynamics, 2002, pp.127-145.

13- Singiresu, S. RAO, "Mechanical vibrations", Perason Printice Hall,

14- P.Kroneld, T.Liedes, K.Nevala, Y.Marjanen,Modeling, "A Selective Hydro pneumatic Suspension Element", University of Oulu, the Thirteenth International Congress on Sound and Vibration, Vienna, Austria, July 2-6, 2006.

15- V.Y.B.Yung, D.J.Cole, "Analysis of High Frequency Forces Generated by Hydraulic Automotive Dampers", 17 ${ }^{\text {th }}$ IAVSD Symposium, 20-25 August, 2001.

16- Yanqing Liu, Jianwu Zhang, "Nonlinear dynamic responses of twin-tube hydraulic shock absorber", PERGAMON, pp.359-365, 2002.

17- Y.Ping, "Experimental and Mathematical Evaluation of Dynamic Behavior of An OilAir Coupling Shock Absorber", Mechanical Systems and Signal Processing, pp.13671379, 17(6) (2003). 